\title{
Climate Change and Childhood Respiratory Health: A Call to Action for Paediatricians
}

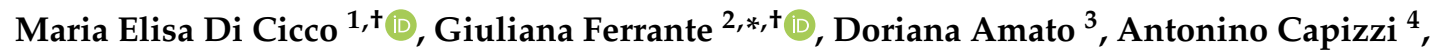 \\ Carlo De Pieri ${ }^{5}{ }^{\circ}$, Valentina Agnese Ferraro ${ }^{6}\left(\mathbb{D}\right.$, Maria Furno ${ }^{4}$, Valentina Tranchino ${ }^{3}$ and \\ Stefania La Grutta ${ }^{7}$ (1) \\ 1 Department of Paediatrics, University Hospital of Pisa, via Roma 67, 56126 Pisa, Italy; maria.dicicco@unipi.it \\ 2 Department of Health Promotion, Mother and Child Care, Internal Medicine and Medical Specialties, \\ University of Palermo, Piazza delle Cliniche 2, 90127 Palermo, Italy \\ 3 Pediatric Medicine Unit and Pediatric Emergency Department, Pediatric Hospital Giovanni XXIII, \\ via Giovanni Amendola 207, 70123 Bari, Italy; dorianamato@libero.it (D.A.); \\ valentina.tranchino@libero.it (V.T.) \\ 4 Pediatrics Unit, S. Paolo and S. Corona Hospital, via Genova 30, 17100 Savona, Italy; \\ anto.capizzi@virgilio.it (A.C.); 2m287@tiscali.it (M.F.) \\ 5 Pediatrics Clinic, Department of Medicine, University Hospital of Udine, Piazzale S.M. della Misericordia 15, \\ 33100 Udine, Italy; carlodepieri@gmail.com \\ 6 Unit of Pediatric Allergy and Respiratory Medicine, Department of Women's and Children's Health, \\ University of Padova, via Nicolò Giustiniani 2, 35128 Padova, Italy; ferrarovalentina@hotmail.com \\ 7 National Research Council of Italy, Institute for Research and Biomedical Innovation, IRIB, \\ Via Ugo La Malfa 153, 90146 Palermo, Italy; stefania.lagrutta@irib.cnr.it \\ * Correspondence: giuliana.ferrante@unipa.it \\ + These authors equally contributed to this study.
}

Received: 14 June 2020; Accepted: 20 July 2020; Published: 24 July 2020 updates

\begin{abstract}
Climate change (CC) is one of the main contributors to health emergencies worldwide. CC appears to be closely interrelated with air pollution, as some pollutants like carbon dioxide $\left(\mathrm{CO}_{2}\right)$, nitrogen oxides (NOx) and black carbon are naturally occurring greenhouse gases. Air pollution may enhance the allergenicity of some plants and, also, has an adverse effect on respiratory health. Children are a uniquely vulnerable group that suffers disproportionately from CC burden. The increasing global warming related to CC has a big impact on plants' lifecycles, with earlier and longer pollen seasons, as well as higher pollen production, putting children affected by asthma and allergic rhinitis at risk for exacerbations. Extreme weather events may play a role too, not only in the exacerbations of allergic respiratory diseases but, also, in favouring respiratory infections. Even though paediatricians are already seeing the impacts of CC on their patients, their knowledge about CC-related health outcomes with specific regards to children's respiratory health is incomplete. This advocates for paediatricians' increased awareness and a better understanding of the CC impact on children's respiratory health. Having a special responsibility for children, paediatricians should actively be involved in policies aimed to protect the next generation from CC-related adverse health effects. Hence, there is an urgent need for them to take action and successfully educate families about CC issues. This paper aims at reviewing the evidence of CC-related environmental factors such as temperature, humidity, rainfall and extreme events on respiratory allergic diseases and respiratory infections in children and proposing specific actionable items for paediatricians to deal with CC-related health issues in their clinical practice.
\end{abstract}

Keywords: allergic rhinitis; asthma; children; climate change; paediatricians; respiratory infections 


\section{Introduction}

Climate change (CC) is a long-term shift in weather conditions identified by changes in the temperature, precipitation, winds and also including extreme weather events. Such events have been defined as "discrete episodes of extreme weather or unusual climate conditions, often associated with deleterious impacts on society or natural systems, defined using some metric to characterise either the meteorological characteristics of the event or the consequent impacts" [1]. Human activity is the main cause of CC, driven primarily by emissions of carbon dioxide $\left(\mathrm{CO}_{2}\right)$ and enhanced by emissions of other greenhouse gases (GHG). The main anthropogenic contributions to the rising GHG levels include burning fossil fuel, livestock farming, industrial activity and deforestation. CC involves all regions worldwide, with environmental outcomes such as melting of the Polar ice, sea rising and extreme weather events, like heatwaves and drought. CC is one of the main contributors to health emergencies worldwide, with a significant impact on human health and potential long-term consequences. Due to CC, $20-40 \%$ of the global human population live in regions that, by the decade 2006-2015, have experienced a warming of more than $1.5^{\circ} \mathrm{C}$ above the period of 1850-1900 in at least one season [2]. One of the most relevant goals of the 2030 Agenda for Sustainable Development is to assure health and well-being for all at all ages. However, this goal cannot be reached without addressing the major health determinants that feature in other goals—-for example, taking urgent action to combat CC [3].

In March 2020, the British Thoracic Society released the position statement, "The Environment and Lung Health 2020" [4], warning on the upcoming risks of people with chronic respiratory diseases who may be particularly sensitive to the impacts of CC.

In this regard, children, particularly under five years of age, are a uniquely vulnerable group that disproportionately suffers from these adverse impacts [5-9]. Children are more susceptible than adults to CC-related respiratory morbidity due to higher ventilation rates, developing respiratory and immunological systems and smaller peripheral airways [10]. Moreover, they usually spend more time playing outdoors during the warm season, thus being at higher risk of dangerous exposure to high temperatures, given their poor ability to maintain optimal internal temperatures under heat stress [11]. As a dramatic consequence, a child born today will live in a world more than four degrees warmer than the preindustrial average, with CC impacting on their health from infancy throughout life [12].

Even though paediatricians are already seeing the impacts of CC on their patients, their knowledge about CC-related health outcomes with specific regards to children respiratory health is incomplete [13]. This advocates for paediatricians' increased awareness and a better understanding of the CC impact on children's respiratory health through integrating evidence into clinical practice and, also, in view of their responsibility to educate families about CC.

This paper aims at reviewing evidence of the burden of CC-related environmental factors such as temperature, humidity, rainfall and extreme events on respiratory allergic diseases and respiratory infections in children and proposing specific actionable items for paediatricians to deal with CC-related health issues in their clinical practice.

\section{Methods}

We searched original papers in English in the PubMed, Scopus and Google Scholar databases using the following keywords, used separately and in combination: Asthma, allergic rhinitis, rhinitis, infections, bronchitis, pneumonia, climate change, pollution, particulate matter, ozone, nitrogen dioxide, allergen and pollen. Age restrictions were set to childhood (birth-18 years). No limitations were set for the date and study country. We also consulted the World Health Organization (WHO) and the Intergovernmental Panel on Climate Change (IPCC) websites and searched the reference lists of the retrieved articles. Exclusion criteria included: commentaries, letters, repeated published articles and case reports. 


\section{Climate Change, Temperature, Pollutants and Pollens: A Harmful Interaction}

CC appears to be closely interrelated with air pollution. In fact, some pollutants mainly derived by anthropogenic sources like $\mathrm{CO}_{2}$ are naturally occurring GHG that contribute to global warming. High temperatures accelerate the production of ozone $\left(\mathrm{O}_{3}\right)$ from its precursors-volatile organic compounds (VOCs), carbon monoxide (CO) and nitrogen oxides (NOx) — so that high levels of this pollutant are concerning large areas of the world. On the other hand, the concentrations of pollutants such as fine particulate matter (PM), polycyclic aromatic hydrocarbons (PAHs) and black carbon are expected to rise due to changes in the temperature, precipitation frequency and forest fires induced by CC [14]. An overabundance of GHG traps a large amount of heat in the atmosphere by absorbing the sun's energy and redirecting it back to the earth's surface, thereby accounting for global warming [15].

High temperatures due to global warming are estimated to have an influence on the start and duration of plant pollen production; as a matter of fact, the increase in fall temperatures results in earlier flowering for many spring-flowering species around the world. Recently, a retrospective analysis of global datasets, with 20 years or more of airborne pollen data in 17 locations in the Northern hemisphere, revealed the significant increase of the pollen load and pollen season duration over time in most analysed locations, in association with the annual cumulative increases in temperature over time. Since air pollen concentrations are supposed to reflect the spatial and temporal changes of plant species, these results suggest that CC, through high temperatures, is already affecting season timing and duration, thereby increasing pollen amounts in the Northern hemisphere [16]. Nonetheless, airborne pollen evolution depends also on pollen production, release and atmospheric dispersion changes. With regards to the European region, it was estimated that, by 2050, airborne ragweed pollen concentrations will be about four times higher than now, mainly due to climate and land-use changes that will extend the ragweed habitat suitability in Northern and Eastern Europe and increase the pollen production in established ragweed areas owing to the increasing $\mathrm{CO}_{2}$ [17].

The interaction between air pollution and aeroallergens has been demonstrated in studies showing that pollutants are able to increase pollen production [18] and to modify pollen morphology and content [19], as well as the chemotactic and the immunomodulatory properties [20]. Open-field studies confirmed these findings. Using an existing temperature $/ \mathrm{CO}_{2}$ gradient between urban and rural areas, Ziska et al. showed that, the average daily values of $\mathrm{CO}_{2}$ concentrations and air temperatures within an urban environment were $30 \%$ to $31 \%$ and 1.8 degrees to $2{ }^{\circ} \mathrm{C}$ higher than those at a rural site. Examining the quantitative and qualitative aspects of ragweed growth and pollen production, they found that ragweed grew faster, flowered earlier and produced significantly greater aboveground biomass and pollen [21].

Interestingly, some studies demonstrated that pollen grains can absorb heavy metals but, also, nitrate and sulphur, while others showed that particles can agglomerate on the surface of pollen grains [22-24]. This pollen-particle interaction may modulate the allergen release and the absorption of pollen proteins to airborne particles, finally contributing to the increase in pollen allergies and asthma in highly polluted areas [19].

Taken together, this evidence is suggestive for a complex interplay amongst CC, air pollution and allergenic pollens that may have a deep impact on respiratory health (Figure 1). 


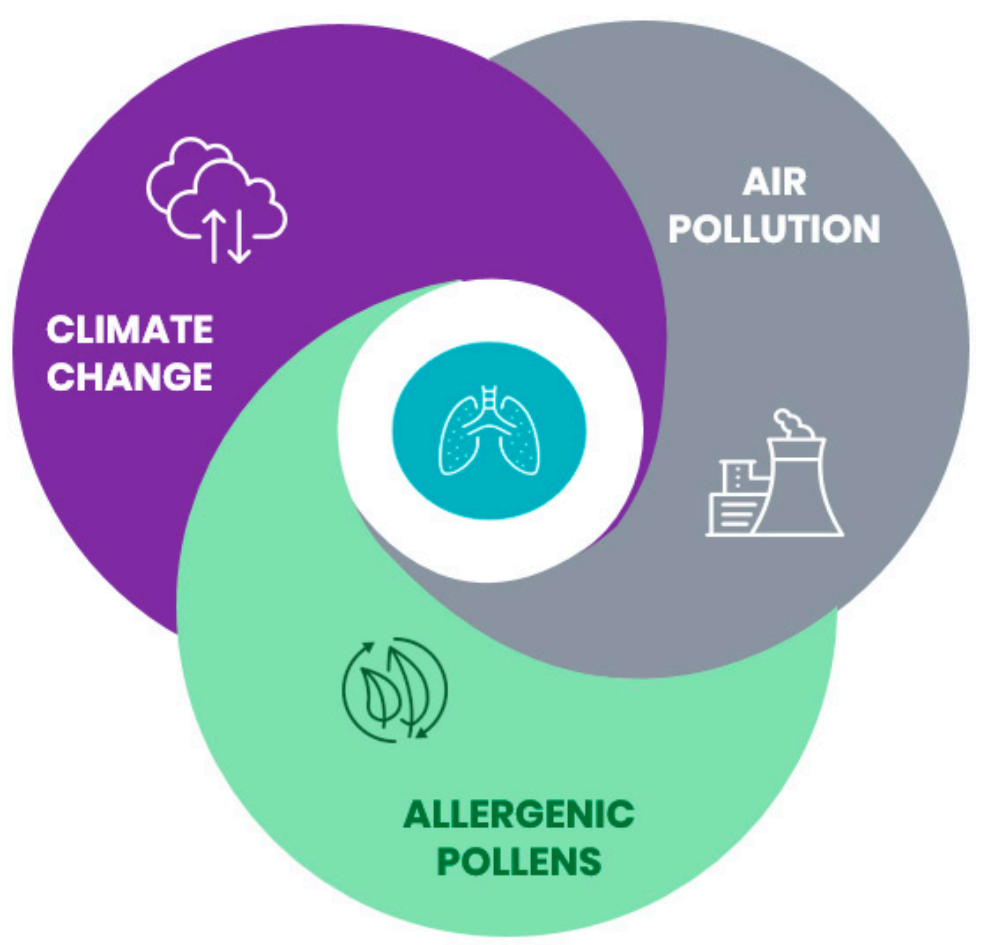

Figure 1. Climate change, air pollution and allergenic pollens are closely interrelated and may impact respiratory health.

\section{The Impact of Climate Change on Paediatric Respiratory Allergic Diseases}

\subsection{Temperature}

With regards to the prevalence of allergic rhinitis (AR), a global ecological analysis in adolescents (222 centres in 94 countries) and in children (132 centres in 57 countries), who had taken part in phase III of the ISAAC (International Studies of Asthma and Allergies in Childhood) study, showed several spatial associations between climatic factors and the prevalence of intermittent and persistent AR symptoms. Monthly data on rhinitis symptoms were collected via standardised parent-completed (for children) or self-completed (for adolescents) questionnaires investigating if problems with sneezing or a runny or blocked nose, eventually accompanied by itchy eyes, apart from a cold or flu, had occurred in the last 12 months. In adolescents, between-country significant associations were found for intermittent rhinitis prevalence and the mean and minimum temperatures $(p<0.01)$; significant within-country associations were found, especially for persistent rhinitis prevalence and the mean and maximum temperatures $(p<0.05)$. Overall, these results indicate that the temperature may contribute to the global increased prevalence of rhinitis symptoms, likely altering the timing, spatial distribution, quality, and quantity of allergenic plants and pollens [25].

A more recent study conducted in China on adults and children showed that pollen-induced AR symptoms were positively correlated with temperature $(p<0.05)$, which, in turn, was positively correlated with the pollen counts $(p<0.001)$, suggesting that a pollen-induced AR prevalence depended on seasonal pollen exposure, which was influenced by local climate factors [26].

With regards to asthma, an ecological study in Australia showed that both cold and hot temperatures may influence the risk of access to emergency care for asthma. In particular, male children and those aged $\leq 4$ years were more susceptible to heat; male children and those aged 10-14 were more susceptible to cold, emphasising the damaging influence of extreme temperatures on the risk of asthma attacks in children [27].

More recently, a study reported lagged effects for temperature-related and paediatric asthma emergency visits, suggesting that children are at risk for increased asthma morbidity when temperatures 
are high, on average, for several days. In detail, estimated Relative Risks (RRs) for maximum temperatures and asthma emergency visits were positive and significant for lag days $1-5$, with the strongest single-day association observed on lag day $2(\mathrm{RR}=1.06,95 \% \mathrm{CI}: 1.03,1.09)$ for a change in the $\mathrm{T}_{\max }$ from $27^{\circ} \mathrm{C}$ to $32{ }^{\circ} \mathrm{C}$ (25th to 75 th percentile) [28].

\subsection{Humidity}

In a previous Turkish study on children, AR was significantly associated with a higher mean yearly outdoor humidity (more than 70\%) $(p<0.05)$ [29]. More recently, the 2007 U.S. National Survey of Children's Health reported that the prevalence of hay fever in children was significantly lower with the second and third quartile mean annual relative humidity $(p \leq 0.01)$, fourth quartile mean annual Palmer Hydrological Drought Index (a lower score reflects dryer conditions, whereas a higher score reflects wetter conditions) $(p=0.02)$ and third and fourth quartile mean annual heating degree days $(p<0.0001)$ but increased with the second, third and fourth quartile mean annual temperatures $(p \leq$ 0.02) and the fourth quartile mean annual precipitation $(p=0.0007)$ [30].

With respect to paediatric asthma, inconsistent results were found, possibly due to the heterogeneity of the study designs and asthma outcomes (morbidity, exacerbations and emergency visits), as well as differences in the geographical environments, type of climates, vegetation, air quality and socioeconomic conditions [6]. A Taiwanese study reported that winter humidity was positively associated with the prevalence of asthma in middle-school students (girls: $p<0.05$ and boys: $p<0.01$ ). [31]. A positive relationship between the mean monthly relative humidity and childhood asthma was reported in a Greek study, where a $10 \%$ increase in humidity was related to a $31 \%$ increase in the probability of having an admission for asthma [32].

Contrariwise, relative humidity was negatively correlated with the asthma admission rates of pre-school $(p<0.01)$ and school-age children $(p<0.001)$ in a Taiwanese study [33]. A population-based study in Spain also showed that relative humidity was negatively associated with asthma in children aged 13 and 14 years $(p<0.0001)$ [34].

\subsection{Extreme Weather Events}

Very recently, scientific interest has been focused on the impact that extreme events may have on childhood asthma. Climatic indices such as the Atlantic multidecadal oscillation (AMO) and the Pacific decadal oscillation (PDO), which are known to modulate drought periods in the contiguous United States, have been positively correlated with asthma death rates in children aged 5-14 years over the period from 1950 to 2015, proving that drought variations and climate variability may be emerging risk factors for asthma mortality [35].

A time-stratified case-crossover study examined the association between the exposure to extreme precipitation events and risk of hospitalisation for asthma in Maryland (USA) between 2000 and 2012: exposures to extreme precipitation, especially during summer, were associated with an increased risk of hospitalisation for asthma. In detail, a higher risk was observed among children aged $\leq 4$ years (OR: 1.20, 95\% CI: $1.05,1.37$ ) and 5 to 17 years (OR: 1.11, 95\% CI: 0.94, 1.30) [36].

Evidence is also growing for the associations between the occurrence of thunderstorms and asthma exacerbations. The so-called "thunderstorm asthma" indicates the bronchospasm developing after a storm during the pollen season, when the pollen grains concentrate at the ground level and, following their rupture due to osmotic shock, they release allergenic particles that can be inhaled, favouring the exacerbation of asthma in people allergic to pollens [37]. An ecological time series analysis conducted for asthma presentations to emergency departments (ED) among children in Melbourne, Australia reported that, during thunderstorms, the daily ED attendance peaked at 70 visits per day, consistent with thunderstorm-associated asthma related to the preceding extreme grass pollen days and strong winds [38]. Nonetheless, it should be pointed out that the risk of asthma exacerbations due to extreme events like thunderstorms in children needs further exploration in order to elucidate the role of concomitant factors, such as viral infections and atopy, in eliciting or worsening symptoms. 


\subsection{Air Pollution}

The complex interplay amongst CC, air pollution and allergenic pollens may contribute to the damage of the airway mucosa through impaired mucociliary clearance, increased permeability with the consequent facilitated penetration of allergens and stimulation of the immune response with an increased production of Immunoglobulins (IgE). Changes in the temperature, precipitation frequency and air stagnation due to CC, as well as forest fires, may release large amounts of PM, PAH and black carbon in the air, which may affect large numbers of exposed children, leading to adverse respiratory outcomes, such as asthma exacerbations [14].

The relative impact of climatic variables and air pollutants on childhood respiratory allergic diseases is an emerging field of research. Noteworthy, a very recent study aimed to quantify the relative impact of meteorological factors and air pollutants on childhood allergic diseases in China showed that $A R$ and asthma prevalence were inversely associated with the daily mean temperature and positively associated with the daily air pressure, $\mathrm{NO}_{2}$ and $\mathrm{O}_{3}$. However, the climatic factors appeared to play a more relevant role than air pollutants. Indeed, the number of diseases attributable to an interquartile range change in climatic factors was greater than those attributable to an interquartile range change in pollutants, emphasising the higher burden of childhood AR and asthma related to climatic variables [39].

Taken together, these data provide evidence of the relevant role of CC-related meteorological conditions on the prevalence of childhood AR, as well as on asthma prevalence and morbidity (Table 1). Of note, an additional impact by air pollutants has been reported on both AR and asthma morbidity.

Table 1. The impact of climate change (CC)-related meteorological conditions on allergic rhinitis (AR) and asthma in children.

\begin{tabular}{ccc}
\hline $\begin{array}{c}\text { CC-Related Meteorological } \\
\text { Conditions }\end{array}$ & AR & Asthma \\
\hline Temperature & $\begin{array}{c}\text { Prevalence of AR symptoms is } \\
\text { positively associated with } \\
\text { temperature [25,26]. }\end{array}$ & $\begin{array}{c}\text { Cold and hot temperatures influence the } \\
\text { risk of access to emergency care [27,28]. }\end{array}$ \\
\hline Humidity & $\begin{array}{c}\text { Inconsistent association with AR } \\
\text { prevalence [29,30]. }\end{array}$ & $\begin{array}{c}\text { Inconsistent association with asthma } \\
\text { prevalence and outcomes [6,31-34]. }\end{array}$ \\
\hline Drought & $\begin{array}{c}\text { Prevalence of AR is lower in areas } \\
\text { with a higher drought index } \\
\text { (wetter conditions) [30]. }\end{array}$ & $\begin{array}{c}\text { Drought variations are positively } \\
\text { correlated with asthma death rates [35]. }\end{array}$ \\
\hline Rainfall & $\begin{array}{c}\text { Minimum and maximum } \\
\text { precipitation are positively } \\
\text { associated with AR symptom } \\
\text { prevalence [25]. }\end{array}$ & $\begin{array}{c}\text { Exposures to extreme precipitation are } \\
\text { associated with an increased risk of } \\
\text { asthma hospitalisation [36] and } \\
\text { epidemics of thunderstorm asthma [38]. }\end{array}$ \\
\hline
\end{tabular}

\section{The Impact of Climate Change on Paediatric Respiratory Infectious Diseases}

The impact of CC on respiratory infectious diseases has recently raised an increasing research interest, particularly in children affected by chronic respiratory diseases [4].

\subsection{Temperature}

In children under five years of age living in the tropical area of Mekong River Delta, through multivariate distributed lag models, it was shown that a $1{ }^{\circ} \mathrm{C}$ increase in the average temperature of the previous day and the previous two days was associated with a $1.9 \%(95 \% \mathrm{CI} 0.3,3.4)$ increase in hospital admissions for respiratory infections; when the cumulative lag model was considered, such an increase was larger: 3.8\% (95\% CI 0.4, 7.2). To explain these findings, the authors proposed the two following reasons: first, younger children do not practice as much outdoor activity as the older ones, 
and second, parents may decide not to take the younger children out when the outdoor temperature is increasing [40].

Both the temperature variability, commonly defined as the temperature change between two neighbouring days (TCN), and the difference between the daily maximum temperature and the daily minimum temperature within one day (DTR) have been recognised as a risk factor for respiratory infections, too. $\mathrm{Xu}$ et al. previously reported that a $\mathrm{TCN} \leq 2{ }^{\circ} \mathrm{C}$ may increase the risk of emergency visits for childhood pneumonia in Brisbane, Australia; this effect lasted around three weeks. Female children, Indigenous children and children aged 5-14 years were the most vulnerable [41]. Moreover, a study in China reported that the DTR was significantly associated with acute bronchitis (defined as an inflammation of the large bronchi mainly characterised by cough, ICD-10 codes: J20) in children, especially when it exceeded $10.9{ }^{\circ} \mathrm{C}$; the largest effect was shown at a three-day lag, with a $1 \%(95 \% \mathrm{CI}$ : $0.5,1.6)$ increase of acute bronchitis cases per $1{ }^{\circ} \mathrm{C}$ increment of the DTR. Female children and children aged $0-4$ years were the most vulnerable [42].

Interestingly, a recent study from South Korea revealed that a "pneumonia temperature", i.e., day-to-day variance in temperature, was associated with an increased risk of emergency visits for pneumonia. In children aged 0-5 years, when the pneumonia temperature was higher than $6{ }^{\circ} \mathrm{C}$, each additional $1{ }^{\circ} \mathrm{C}$ increase resulted in a $1.89 \%(95 \% \mathrm{CI}$ : 1.34, 2.67) increase in the relative risk for an emergency visit due to pneumonia. Warm average temperatures and large DTRs showed protective effects, even if the latter might have been influenced by some limitations, such as not considering the effect of modifiers like the season and socioeconomic status [43].

\subsection{Humidity}

Of note, the burden of higher temperatures seems to be counterweighted by an increased humidity; in addition, the activity of many respiratory viruses, such as respiratory syncytial virus (RSV), influenza A and rhinovirus, is positively correlated to the relative and/or absolute humidity [44-46]. In the Netherlands, during the period 1998-2005, the relative humidity was positively associated with RSV activity for up to four weeks $(p<0.01)$, suggesting more RSV activity when the relative humidity increased and, therefore, supporting the role of climatic conditions in the dynamics of RSV infection [45]. Accordingly, in a study conducted in an urban area in Italy, the number of RSV-positive infants was correlated with the relative humidity $(p<0.001)$ positively and with temperature $(p<0.001)$ negatively [47].

\subsection{Extreme Weather Events}

An effect of CC seems to be the higher frequency of rainfall events, with the consequence of a larger proportion of people being exposed to pluvial floodwater in both high and low-income regions. On the other hand, urbanisation also contributes to the increased risk of flooding through relevant changes of the land cover.

Potential adverse health impacts of floods include respiratory infections. An increased risk of 1.66 (95\% CI: 1.57, 1.74) for hospital admissions due to acute lower respiratory infections in children aged 0-15 years has been reported in the Mekong River Delta area [48]. Extreme rainfall was significantly associated with emergency visits for influenza in children aged 5-18 years (OR $=1.32$ (95\% CI: 1.14, 1.52)) in the North-eastern U.S. area, too. Notwithstanding the strict methodology of this case-crossover study, including climatological and air pollutants, temperature, relative humidity and barometric pressure in the analysis as potential confounders, the authors recognise that further studies are required to clarify what could be the role of indoor crowding in this association [49]. More recently, a cross-sectional survey in 60 Dutch locations with reported flooding did not find a significant association between the exposure to pluvial floodwater and acute respiratory infections in children (OR $=1.6(95 \%$ CI: 0.6, 4.0)) [50]. 
In a Brazilian study, the combination of rainfall, air temperature, humidity and wind speed showed relatively high correlation coefficients in relation to hospital admissions for pneumonia in children $\left(\mathrm{R}_{2}=68.4 \%\right)$ and infants $\left(\mathrm{R}_{2}=71.8 \%\right)$ [51].

Extreme weather events such as heatwaves have become one of the most serious consequences of $\mathrm{CC}$, which may promote or aggravate respiratory diseases. In California, during heatwaves, emergency department visits for acute respiratory infections increased among children aged 0-4 years (RR: 1.05; 95\% CI: 1.04, 1.07) [11]. More recently, an ecological study in China in the period 2010-2012-during which four heatwaves occurred-found significant positive associations of respiratory infectious diseases with heatwaves. In particular, in children aged 4-17 years, the strongest effect was shown at $\operatorname{lag} 0(\mathrm{RR}=1.764 ; 95 \% \mathrm{CI}: 1.479,2.103)$ for upper respiratory tract infections. The results were adjusted for meteorological (temperature, rainfall, wind speed, pressure, humidity and sunshine hours) and air pollution factors, including the level of several atmospheric pollutants (nitrogen oxides, sulphur dioxide, total suspended particulates, etc.) [52].

Taken together, these data provide evidence of the role of CC-related factors such as high temperatures, temperature variability, humidity and extreme weather events on respiratory infection morbidities in children.

\section{The Role of Paediatricians: A Call to Action}

Since CC may undermine the last half-century of gains in global child health $[5,13]$, there is an urgent need for health professionals to successfully educate citizens about CC issues and to engage them in preventive and adaptive responses [53].

In order to minimise CC effects on respiratory health, physicians should consider measures such as learning more about CC health impacts, understanding pollen and air quality forecasts, teaching patients and their families to find available pollen data and counselling caregivers to minimise exposures and maximise the management of the respiratory symptoms of their children [54,55], as well as using anticipatory guidance to discuss CC with families and serving as a personal role model [56].

Paediatricians, who bear a special responsibility for children, should be engaged in strategies to address CC by alerting patients and their families on health implications and, also, counselling on the personal and environmental benefits of a transition to active transport and to a plant-based diet [57-60]. Indeed, consuming healthy diets low in red meat and processed meats and rich in plant-based foods has been suggested to substantially contribute to reducing $\mathrm{CO}_{2}$ emissions, crop damage and extreme weather [61]. However, interventions to address CC encompass not only behavioural changes but, also, technological advances and political action. Paediatricians should exert pressure on governments, corporations and private institutions to take mitigation strategies for CC. They also should be involved in continuing medical education activities within teaching modules, as well as residency training programmes and conferences, in order to strengthen their leadership capacity in the area of children's environmental health [57].

Suggested actions for paediatricians to improve their daily clinical practice are summarised below.

- Refer to existing resources that provide climate-smart healthcare practices (e.g., American Academy of Pediatrics policy statement on global CC and children's health, http://pediatrics.aappublications. org/content/136/5/992).

- Teach parents and caregivers to minimise their own carbon footprint (e.g., Centers for Disease Control and Prevention. Sustainable Lifestyle, https://www.cdc.gov/sustainability/lifestyle/index. htm and United States Environmental Protection Agency Carbon Footprint Calculator, https: //www3.epa.gov/carbon-footprint-calculator/).

- Counsel patients to monitor the local information on weather, heat waves, air quality and pollen forecasts in order to set preventive measures and developing corrective behaviours for minimising adverse environmental exposures (e.g., maintain regular controller treatment for symptom control, carry a rescue inhaler on high-risk days, limit time outdoors and avoid intense or prolonged exertions outdoors). 
- Modify the anticipatory guidance for CC-related impacts, especially for children with chronic respiratory diseases (e.g., adequate hydration and cooling on hot days and advice for vulnerable individuals to avoid intense outdoor exercise and stay indoors or wear protective masks when the air quality is in the harmful range).

- Teach patients to recognise respiratory symptoms that may be related to extreme weather events (e.g., rhinorrhoea, sneezing, itching, cough, phlegm, wheezing, shortness of breath and chest tightness).

- Counsel parents and caregivers on the personal and environmental benefits of transitioning to active transport (e.g., walking, jogging and bicycling) and a plant-based diet (e.g., Mediterranean diet), as consuming diets low in red meats and processed meats and rich in plant-based foods has been suggested to substantially contribute to reducing $\mathrm{CO}_{2}$ emissions, crop damage and extreme weather.

Paediatricians should also play a central role at an institutional level in the global challenge imposed by CC by helping to build a broader coalition across disciplines to properly address CC $[60,62]$; advocating for local, national, and international policies aimed at reducing GHG emissions and taking part in multidisciplinary collaborations with other health professionals, civil authorities in charge of emergency preparedness programmes, city planners and architects, in order to develop new adaptation measures and strengthen existing public health strategies [63,64].

\section{Conclusions}

$\mathrm{CC}$ is currently one of the most dangerous threats to children's health. Children are uniquely vulnerable to CC, due to age-specific characteristics. There has been increasing interest in CC's impact on their respiratory health.

Paediatricians can play a relevant role in a range of actions, which include implementing and promoting strategies to reduce GHG and providing education to children and their caregivers but, also, being involved in policy work. In this context, they should collaborate with decision-makers, including local governments, academia and school boards and community leaders. Paediatricians can also conduct health assessments, actively support policies to reduce harmful exposures and advocate for protecting children's health [65]. Such actionable items should be acknowledged by paediatricians to fully address CC-related health issues in their clinical practice, with the aim of reducing the risks and improving the health of children.

Author Contributions: Conceptualisation, M.E.D.C. and G.F.; methodology, M.E.D.C. and G.F.; writing-original draft preparation, M.E.D.C., G.F., D.A., A.C., C.D.P., V.A.F., M.F. and V.T.; writing-review and editing, S.L.G. and supervision, S.L.G. All authors have read and agreed to the published version of the manuscript.

Funding: This research received no external funding.

Conflicts of Interest: The authors declare no conflict of interest.

\section{References}

1. Stott, P.; Christidis, N.; Otto, F.E.L.; Sun, Y.; Vanderlinden, J.; Van Oldenborgh, G.J.; Vautard, R.; Von Storch, H.; Walton, P.; Yiou, P.; et al. Attribution of extreme weather and climate-related events. Wiley Interdiscip. Rev. Clim. Chang. 2016, 7, 23-41. [CrossRef] [PubMed]

2. First, P.J. Global Warming of $1.5^{\circ} \mathrm{C}$. Available online: https://www.ipcc.ch/sr15/ (accessed on 1 June 2020).

3. Clark, H.; Coll-Seck, A.M.; Banerjee, A.; Peterson, S.; Dalglish, S.L.; Ameratunga, S.; Balabanova, D.; Bhan, M.K.; Bhutta, Z.A.; Borrazzo, J.; et al. A future for the world's children? A WHO-UNICEF-Lancet Commission. Lancet 2020, 395, 605-658. [CrossRef]

4. Singh, S.J.; Barradell, A.C.; Greening, N.J.; Bolton, C.E.; Jenkins, G.; Preston, L.; Hurst, J.R. The British Thoracic Society survey of rehabilitation to support recovery of the Post Covid-19 population. Environ. Lung Health 2020. [CrossRef]

5. Ahdoot, S.; Pacheco, S.E. Global climate change and children's health. Pediatrics 2015, 136, e1468-e1484. [CrossRef] 
6. Gao, J.; Sun, Y.; Lu, Y.; Li, L. Impact of Ambient Humidity on Child Health: A Systematic Review. PLoS ONE 2014, 9, e112508. [CrossRef] [PubMed]

7. Kim, J.J. Ambient Air Pollution: Health Hazards to Children. Pediatrics 2004, 114, 1699-1707. [CrossRef] [PubMed]

8. Nitschke, M.; Tucker, G.; Hansen, A.; Williams, S.; Zhang, Y.; Bi, P. Impact of two recent extreme heat episodes on morbidity and mortality in Adelaide, South Australia: A case-series analysis. Environ. Health 2011, 10, 42. [CrossRef] [PubMed]

9. Xu, Z.; Sheffield, P.; Hu, W.; Su, H.; Yu, W.; Qi, X.; Tong, S. Climate Change and Children's Health-A Call for Research on What Works to Protect Children. Int. J. Environ. Res. Public Health 2012, 9, 3298-3316. [CrossRef]

10. Moya, J.; Bearer, C.F.; Etzel, R.A. Children's behavior and physiology and how it affects exposure to environmental contaminants. Pediatrics 2004, 113 (Suppl. S4), 996-1006.

11. Knowlton, K.; Rotkin-Ellman, M.; King, G.; Margolis, H.G.; Smith, D.; Solomon, G.; Trent, R.; English, P. The 2006 California Heat Wave: Impacts on Hospitalizations and Emergency Department Visits. Environ. Health Perspect. 2009, 117, 61-67. [CrossRef]

12. Watts, N.; Amann, M.; Arnell, N.; Ayeb-Karlsson, S.; Belesova, K.; Boykoff, M.; Byass, P.; Cai, W.; Campbell-Lendrum, D.; Capstick, S.; et al. The 2019 report of The Lancet Countdown on health and climate change: Ensuring that the health of a child born today is not defined by a changing climate. Lancet 2019, 394, 1836-1878. [CrossRef]

13. Philipsborn, R.P.; Chan, K. Climate Change and Global Child Health. Pediatrics 2018, 141, e20173774. [CrossRef] [PubMed]

14. Perera, F.P. Multiple Threats to Child Health from Fossil Fuel Combustion: Impacts of Air Pollution and Climate Change. Environ. Health Perspect. 2017, 125, 141-148. [CrossRef] [PubMed]

15. D'Amato, G.; Cecchi, L.; D'Amato, M.; Annesi-Maesano, I. Climate change and respiratory diseases. Eur. Respir. Rev. 2014, 23, 161-169. [CrossRef]

16. Ziska, L.H.; Makra, L.; Harry, S.K.; Bruffaerts, N.; Hendrickx, M.; Coates, F.; Saarto, A.; Thibaudon, M.; Oliver, G.; Damialis, A.; et al. Temperature-related changes in airborne allergenic pollen abundance and seasonality across the northern hemisphere: A retrospective data analysis. Lancet Planet. Health 2019, 3, e124-e131. [CrossRef]

17. Hamaoui-Laguel, L.; Vautard, R.; Liu, L.; Solmon, F.; Viovy, N.; Khvorostyanov, D.; Essl, F.; Chuine, I.; Colette, A.; Semenov, M.; et al. Effects of climate change and seed dispersal on airborne ragweed pollen loads in Europe. Nat. Clim. Chang. 2015, 5, 766-771. [CrossRef]

18. Wayne, P.M.; Foster, S.; Connolly, J.; Bazzaz, F.; Epstein, P. Production of allergenic pollen by ragweed (Ambrosia artemisiifolia L.) is increased in $\mathrm{CO}_{2}$-enriched atmospheres. Ann. Allergy Asthma Immunol. 2002, 88, 279-282. [CrossRef]

19. Traidl-Hoffmann, C.; Kasche, A.; Menzel, A.; Jakob, T.; Thiel, M.; Ring, J.; Behrendt, H. Impact of Pollen on Human Health: More Than Allergen Carriers? Int. Arch. Allergy Immunol. 2003, 131, 1-13. [CrossRef]

20. Beck, I.; Jochner, S.; Gilles, S.; McIntyre, M.; Buters, J.; Schmidt-Weber, C.B.; Behrendt, H.; Ring, J.; Menzel, A.; Traidl-Hoffmann, C. High Environmental Ozone Levels Lead to Enhanced Allergenicity of Birch Pollen. PLoS ONE 2013, 8, e80147. [CrossRef]

21. Ziska, L.H.; Gebhard, D.E.; Frenz, D.A.; Faulkner, S.; Singer, B.D.; Straka, J.G. Cities as harbingers of climate change: Common ragweed, urbanization, and public health. J. Allergy Clin. Immunol. 2003, 111, 290-295. [CrossRef]

22. Kainka-Stänicke, E.; Behrendt, H.; Friedrichs, K.H.; Tomigas, R. Morphological alterations of pollen and spores induced by airborne pollutants: Observations form two differently polluted areas in West Germany. Allergy 1988, 43, 57.

23. Kainka-Stänicke, E.; Behrendt, H.; Friedrichs, K.H.; Tomigas, R. Surface alterations of pollen and spores by particulate air pollutants. J. Hyg. Environ. Med. 1989, 188, 516.

24. Behrendt, H.; Becker, W.M.; Friedrichs, K.H.; Darsow, U.; Tomingas, R. Interaction between aeroallergens and airborne particulate matter. Int. Arch. Allergy Immunol. 1992, 99, 425-428. [CrossRef]

25. Fuertes, E.; Butland, B.K.; Anderson, H.R.; Carlsten, C.; Strachan, D.P.; Brauer, M.; ISAAC Phase Three Study Group. Childhood intermittent and persistent rhinitis prevalence and climate and vegetation: A global ecologic analysis. Ann. Allergy. Asthma. Immunol. 2014, 113, 386-392. [CrossRef] [PubMed] 
26. Wang, X.-Y.; Ma, T.; Zhuang, Y.; Ning, H.-Y.; Shi, H.-Y.; Yu, R.-L.; Yan, D.; Huang, H.-D.; Bai, Y.-F.; Shan, G.-L.; et al. Prevalence of pollen-induced allergic rhinitis with high pollen exposure in grasslands of northern China. Allergy 2018, 73, 1232-1243. [CrossRef]

27. Xu, Z.; Huang, C.; Hu, W.; Turner, L.; Su, H.; Tong, S. Extreme temperatures and emergency department admissions for childhood asthma in Brisbane, Australia. Occup. Environ. Med. 2013, 70, 730-735. [CrossRef] [PubMed]

28. O'Lenick, C.R.; Winquist, A.; Chang, H.; Kramer, M.R.; Mulholland, J.A.; Grundstein, A.J.; Ebelt, S.T. Evaluation of individual and area-level factors as modifiers of the association between warm-season temperature and pediatric asthma morbidity in Atlanta, GA. Environ. Res. 2017, 156, 132-144. [CrossRef]

29. Kurt, E.; Metintas, S.; Basyigit, I.; Bulut, I.; Coskun, E.; Dabak, S.; Deveci, F.; Fidan, F.; Kaynar, H.; Uzaslan, E.K.; et al. Prevalence and risk factors of allergies in Turkey: Results of a multicentric cross-sectional study in children. Pediatr. Allergy Immunol. 2007, 18, 566-574. [CrossRef]

30. Silverberg, J.I.; Braunstein, M.; Lee-Wong, M. Association between climate factors, pollen counts, and childhood hay fever prevalence in the United States. J. Allergy Clin. Immunol. 2015, 135, 463-469.e5. [CrossRef]

31. Guo, Y.L.; Lin, Y.-C.; Sung, F.C.; Huang, S.L.; Ko, Y.C.; Lai, J.S.; Su, H.-J.; Shaw, C.K.; Lin, R.S.; Dockery, D.W. Climate, traffic-related air pollutants, and asthma prevalence in middle-school children in taiwan. Environ. Health Perspect. 1999, 107, 1001-1006. [CrossRef]

32. Nastos, P.T.; Paliatsos, A.G.; Papadopoulos, M.; Bakoula, C.; Priftis, K.N. The Effect of Weather Variability on Pediatric Asthma Admissions in Athens, Greece. J. Asthma 2008, 45, 59-65. [CrossRef]

33. Xirasagar, S.; Lin, H.-C.; Liu, T.-C. Seasonality in pediatric asthma admissions: The role of climate and environmental factors. Eur. J. Pediatr. 2006, 165, 747-752. [CrossRef] [PubMed]

34. Arnedo-Pena, A.; Garcia-Marcos, L.; Fernández-Espinar, J.F.; Bercedo-Sanz, A.; Aguinaga-Ontoso, I.; González-Díaz, C.; Urueña, I.L.C.; Busquet-Monge, R.; Suárez-Varela, M.M.; De Andoin, N.G.; et al. Sunny hours and variations in the prevalence of asthma in schoolchildren according to the International Study of Asthma and Allergies (ISAAC) Phase III in Spain. Int. J. Biometeorol. 2010, 55, 423-434. [CrossRef] [PubMed]

35. Bonomo, S.; Ferrante, G.; Palazzi, E.; Pelosi, N.; Lirer, F.; Viegi, G.; La Grutta, S. Evidence for a link between the Atlantic Multidecadal Oscillation and annual asthma mortality rates in the US. Sci. Rep. 2019, 9, 11683. [CrossRef] [PubMed]

36. Soneja, S.; Jiang, C.; Fisher, J.; Upperman, C.R.; Mitchell, C.; Sapkota, A. Exposure to extreme heat and precipitation events associated with increased risk of hospitalization for asthma in Maryland, U.S.A. Environ. Health 2016, 15, 57. [CrossRef] [PubMed]

37. D'Amato, G.; Liccardi, G.; Frenguelli, G. Thunderstorm-asthma and pollen allergy. Allergy 2007, 62, 11-16. [CrossRef]

38. Erbas, B.; Akram, M.; Dharmage, S.C.; Tham, R.; Dennekamp, M.; Newbigin, E.; Taylor, P.; Tang, M.L.; Abramson, M.J. The role of seasonal grass pollen on childhood asthma emergency department presentations. Clin. Exp. Allergy 2012, 42, 799-805. [CrossRef]

39. Hu, Y.; Xu, Z.; Jiang, F.; Li, S.; Liu, S.; Wu, M.; Yan, C.; Tan, J.; Yu, G.; Hu, Y.; et al. Relative impact of meteorological factors and air pollutants on childhood allergic diseases in Shanghai, China. Sci. Total. Environ. 2020, 706, 135975. [CrossRef]

40. Phung, D.T.; Rutherford, S.; Chu, C.; Wang, X.; Nguyen, M.; Nguyen, N.H.; Do, C.M.; Nguyen, T.; Huang, C. Temperature as a risk factor for hospitalisations among young children in the Mekong Delta area, Vietnam. Occup. Environ. Med. 2015, 72, 529-535. [CrossRef]

41. Xu, Z.; Hu, W.; Tong, S. Temperature variability and childhood pneumonia: An ecological study. Environ. Health 2014, 13, 51. [CrossRef]

42. Xie, M.-Y.; Ni, H.; Zhao, D.-S.; Cheng, J.; Wen, L.-Y.; Li, K.-S.; Yang, H.-H.; Wang, S.-S.; Zhang, H.; Wang, X.; et al. Effect of diurnal temperature range on the outpatient visits for acute bronchitis in children: A time-series study in Hefei, China. Public Health 2017, 144, 103-108. [CrossRef] [PubMed]

43. Sohn, S.; Cho, W.; Kim, J.A.; Altaluoni, A.; Hong, K.; Chun, B.C. 'Pneumonia Weather': Short-term Effects of Meteorological Factors on Emergency Room Visits Due to Pneumonia in Seoul, Korea. J. Prev. Med. Public Health 2019, 52, 82-91. [CrossRef] [PubMed]

44. McMichael, A.E.; Woodruff, R.; Hales, S. Climate change and human health: Present and future risks. Lancet 2006, 367, 859-869. [CrossRef] 
45. Meerhoff, T.; Paget, J.W.; Kimpen, J.L.; Schellevis, F. Variation of Respiratory Syncytial Virus and the Relation with Meteorological Factors in Different Winter Seasons. Pediatr. Infect. Dis. J. 2009, 28, 860-866. [CrossRef]

46. Mirsaeidi, M.; Motahari, H.; Khamesi, M.T.; Sharifi, A.; Campos, M.A.; Schraufnagel, D. Climate Change and Respiratory Infections. Ann. Am. Thorac. Soc. 2016, 13, 1223-1230. [CrossRef]

47. Nenna, R.; Evangelisti, M.; Frassanito, A.; Scagnolari, C.; Pierangeli, A.; Antonelli, G.; Nicolai, A.; Arima, S.; Moretti, C.; Papoff, P.; et al. Respiratory syncytial virus bronchiolitis, weather conditions and air pollution in an Italian urban area: An observational study. Environ. Res. 2017, 158, 188-193. [CrossRef]

48. Phung, D.T.; Huang, C.; Rutherford, S.; Chu, C.; Wang, X.; Nguyen, M. Association between annual river flood pulse and paediatric hospital admissions in the Mekong Delta area. Environ. Res. 2014, 135, 212-220. [CrossRef]

49. Smith, G.S.; Messier, K.P.; Crooks, J.L.; Wade, T.J.; Lin, C.J.; Hilborn, E.D. Extreme precipitation and emergency room visits for influenza in Massachusetts: A case-crossover analysis. Environ. Health 2017, 16, 108. [CrossRef]

50. Mulder, A.C.; Pijnacker, R.; De Man, H.; Van De Kassteele, J.; Van Pelt, W.; Mughini-Gras, L.; Franz, E. "Sickenin' in the rain"-increased risk of gastrointestinal and respiratory infections after urban pluvial flooding in a population-based cross-sectional study in the Netherlands. BMC Infect. Dis. 2019, 19, 377. [CrossRef]

51. De Souza, A.; Fernandes, W.A.; Pavão, H.G.; Lastoria, G.; Albrez, E.D.A. Potential impacts of climate variability on respiratory morbidity in children, infants, and adults. J. Bras. Pneumol. 2012, 38, 708-715.

52. Zhang, A.; Hu, W.; Li, J.; Wei, R.; Lin, J.; Ma, W. Impact of heatwaves on daily outpatient visits of respiratory disease: A time-stratified case-crossover study. Environ. Res. 2019, 169, 196-205. [CrossRef]

53. Maibach, E.; Nisbet, M.C.; Baldwin, P.; Akerlof, K.L.; Diao, G. Reframing climate change as a public health issue: An exploratory study of public reactions. BMC Public Health 2010, 10, 299. [CrossRef]

54. D’Amato, G.; Rottem, M.; Dahl, R.; Blaiss, M.S.; Ridolo, E.; Cecchi, L.; Rosario, N.; Motala, C.; Ansotegui, I.; Annesi-Maesano, I. Climate Change, Migration, and Allergic Respiratory Diseases: An Update for the Allergist. World Allergy Organ. J. 2011, 4, 121-125. [CrossRef] [PubMed]

55. Shea, K.M.; Truckner, R.T.; Weber, R.W.; Peden, D.B. Climate change and allergic disease. J. Allergy Clin. Immunol. 2008, 122, 443-453. [CrossRef] [PubMed]

56. Voelker, R. Climate Change Puts Children in Jeopardy. J. Am. Med. Assoc. 2009, 301, 2197-2199. [CrossRef] [PubMed]

57. Bhutta, Z.A.; Aimone, A.; Akhtar, S. Climate change and global child health: What can paediatricians do? Arch. Dis. Child. 2019, 104, 417-418. [CrossRef]

58. Isaacs, D. Climate change: The moral role of paediatricians. J. Paediatr. Child Health 2015, 51, $843-844$. [CrossRef]

59. Seal, A.; Vasudevan, C. Climate change and child health. Arch. Dis. Child. 2011, 96, 1162-1166. [CrossRef]

60. Winkler, M.S.; Röösli, M.; Ragettli, M.S.; Cissé, G.; Müller, P.; Utzinger, J.; Perez, L. Mitigating and adapting to climate change: A call to public health professionals. Int. J. Public Health 2015, 60, 631-632. [CrossRef]

61. Maxwell, J.; Blashki, G. Teaching about Climate Change in Medical Education: An Opportunity. J. Public Health Res. 2016, 5, 5. [CrossRef]

62. Moser, A.M.; Stigler, F.L.; Haditsch, B. Physicians' responsibility for planetary health. Lancet Planet. Health 2017, 1, e56. [CrossRef]

63. Ferrante, G.; Asta, F.; Cilluffo, G.; De Sario, M.; Michelozzi, P.; La Grutta, S. The effect of residential urban greenness on allergic respiratory diseases in youth: A narrative review. World Allergy Organ. J. 2020, 13, 100096. [CrossRef] [PubMed]

64. Sheffield, P.E.; Weinberger, K.R.; Kinney, P.L. Climate Change, Aeroallergens, and Pediatric Allergic Disease. Mt. Sinai J. Med. J. Transl. Pers. Med. 2011, 78, 78-84. [CrossRef] [PubMed]

65. World Health Organization. Air Pollution and Child Health: Prescribing Clean Air; 2018 (WHO/CED/PHE/18.01); Licence: CC BY-NC-SA 3.0 IGO; WHO: Geneva, Switzerland, 2018.

(C) 2020 by the authors. Licensee MDPI, Basel, Switzerland. This article is an open access article distributed under the terms and conditions of the Creative Commons Attribution (CC BY) license (http://creativecommons.org/licenses/by/4.0/). 